\title{
Springs with two Way Shape Memory Obtained by Stabilised Stress Induced Martensite Training Methods
}

\author{
J.M. Guilemany, B.G. Mellor*, J. Fernández, R. Franch and S.E. Willott* \\ Metalurgia Física-Cienca de Materiales, Dept. de Ingeniería Química y Metalurgia, Facultad de Química, \\ Martí i Franquès, 1. E-08028 Barcelona, Spain \\ * Engineering Materials, The University, Southampton SO9 5NH, U.K.
}

\begin{abstract}
The influence of the amount of deformation induced during training and the time elapsed between quenching after betatising and training of the two way shape memory effect (TWSME) developed in $\mathrm{Cu}-\mathrm{Zn}$-Al shape memory compression springs is studied. Training was carried out by the constraint ageing (stabilised stress induced martensite) method and TWSME was assessed by thermal cycling between $20^{\circ} \mathrm{C}$ and $100^{\circ} \mathrm{C}$. An increase in TWSME is obtained on increasing training strain. This is a consequence of the greater volume of material trained at higher training strains. The time between quenching and the commencement of training affects substantially the amount of TWSME developed. This is a consequence of the quenched in vacancy supersaturation enhacing the "stabilisation" ${ }^{1}$ of the thermal martensite originally formed on quenching.
\end{abstract}

\section{INTRODUCTION}

The two way shape memory effect (TWSME) can be obtained by various thermomechanical training methods [1,2], the object of which is to obtain in succesive martensitic transformations undergone by the material during its industrial use the preferential growth of one martensite variant at the expense of others. One of the training methods developed in recent years obtains this preferred growth by means of stabilised stress induced martensite (SSIM) [3-5].

The training of shape memory alloys by the SSIM method has the training temperature, training time and deformation induced during training as the principal variables. In addition the vacancy supersaturation and degree of order in the $\beta$ parent phase, as determined by the heat treatment prior to the deformation induced during training and the time interval between quenching and training on the amount of TWSME obtained in compression springs made from a $\mathrm{Cu}-\mathrm{Zn}-\mathrm{Al}$ material, training taking place under a constant compressive constraint.

\section{EXPERIMENTAL METHOD}

The alloy used in this study was a commercial polycrystalline material of chemical composition $73.9 \% \mathrm{Cu}, 20.0 \% \mathrm{Zn}, 5.7 \% \mathrm{Al}, 0.15 \% \mathrm{Zr}, 0.15 \% \mathrm{Si}, 0.1 \%$ Fe with a martensitic start

(1) Although the term" stabilised martensite" is widely used in the literature to describe this phenomenon in order to avoid any ambiguity in the present paper the term "retained martensite " is preferred so as to distinguish this type of martensite clearly from the stabilised stress induced martensite formed by training. 
transformation temperature $\left(\mathrm{M}_{\mathrm{s}}\right)$ of $53^{\circ} \mathrm{C}$. Compression springs made from wire $1.7 \mathrm{~mm}$ in diameter with four effective coils and ground ends were kindly supplied by Memory Metals Limited of Ipswich, UK. The height of the springs was $19 \mathrm{~mm}$ and their mean diameter $10 \mathrm{~mm}$.

Before training the springs were held in the $B$ phase region at $850^{\circ} \mathrm{C}$ for 15 minutes followed by direct quenching into water at $20^{\circ} \mathrm{C}$. The training process, which began immediately after quenching, consisted of the application of a compressive force to the spring so as to achieve a fixed deflection. This will favour the growth of the variants which best accommodate the deformation sustained. The spring, thus constrained, was aged at the training temperature for the training time, the object being to stabilise those martensite variants favoured by the applied deformation.

The amount of TWSME was assessed by the method shown in Figure 1 an the TWSME\% evaluated by the expression :

$$
\text { TWSME } 8=\frac{h_{h}-h_{c}}{h_{0}-h_{t I}} \times 100
$$

where $h_{h}$ is the height of the spring in the $B$ phase (hot shape), $h_{c}$ is the height of the spring in the martensitic state (cold shape), $h_{0}$ the original height of the spring before training and $h_{t r}$ the height of the spring during training.

Deflections during training equivalent of shear strains at the outer fiber of the wire of $0.8 \%, 1 \%, 1.25 \%$ and $1.6 \%$ were applied and the springs were held at the training temperature $\left(\mathrm{T}_{\mathrm{tr}}\right)$ of $110^{\circ} \mathrm{C}$ for the training time $\left(\mathrm{t}_{\mathrm{tr}}\right)$ of 30 minutes. These values of temperature and time were chosen as they correspond to the optimum conditions for training this alloy in his state [6,7]. The stability of the TWSME was evaluated by thermal cycling the springs, in the absence of any external load, between two baths at $20^{\circ} \mathrm{C}$ and $100^{\circ} \mathrm{C}$. The height of the springs was measured at each of these temperatures ( $h_{c}$ and $h_{b}$ respectively). Thermal cycling was carried out shortly after training.

To asses the influence of time between quenching into water at $20^{\circ} \mathrm{C}$ and the commencement of training on the amount of TWSME developed, springs were allowed to remain at room temperature for times of 2 to 60 minutes before being trained, the training conditions consisting of compression to a length of $13 \mathrm{~mm}$ (equivalent to a maximum surface shear strain of approximately $1.8 \%$ ) and constraint ageing at $1500^{\circ} \mathrm{C}$ for 30 minutes.

Optical and scanning electron metallography (SEM ISI SS60) were used to relate the effects of training treatment on the microstructure of the material The chemical composition of the phases and precipitates in the material was obtained by Energy Dispersive X-Ray Spectroscopy (EDS Kevex Quantum).

\section{RESULTS AND DISCUSSION}

A metallographic study of the material before the $850^{\circ} \mathrm{C}$ heat treatment revealed it to possess a duplex $\alpha+B$ structure with a strong texture in the wire drawing direction, Figure 2 . The soft $\alpha$ is present in elongated bands. A large number of precipitates were observed throughout the matrix. These precipitates can be classified basically into three types according to their composition and morphology. Firstly, precipitates with a mean size of $1 \mu \mathrm{m}$ situated preferentially at grain boundaries. Their composition was $78 \% \mathrm{Cu}, 8 \% \mathrm{Zn}, 8 \% \mathrm{Al}, 6 \% \mathrm{Si}$ Secondly, grain boundary precipitates, with a rounded morphology of $1.5 \mu \mathrm{m}$ mean size, with a composition of $48 \% \mathrm{Cu}, 26 \% \mathrm{Zr}, 13 \% \mathrm{Al}, 9 \% \mathrm{Zn}, 4 \% \mathrm{Si}$. Finally, the third type of precipitate has either an elongated nature, or form groups of fine precipitates, of length $2.5 \mu \mathrm{m}$, with an average composition of $44 \% \mathrm{Zr}, 31 \% \mathrm{Cu}, 17 \% \mathrm{Si}, 3 \% \mathrm{Zn}, 3 \% \mathrm{Al}, 2 \% \mathrm{Fe}$. EDS did not detect the presence of iron in the matrix and thus all the iron is in the latter precipitate. 
After the heat treatment at $850^{\circ} \mathrm{C}$ and water quench before training the microstructure is martensitic, Figure 3 , with a large number of different variants with different orientations. The morphology, distribution and composition of the precipitates did not change with the heat treatments performed on the springs.

Figure 4 shows the TWSME \% as a function of the various levels of training strains applied during training. When the material is deformed to its coil bound state, i.e. with the maximum deformation applied during training, the largest amount of TWSME is obtained wich is approximately $60 \%$. The increase of TWSME with deformation applied during training is quite pronounced for training deformations of less than $1.25 \%$ while above that figure the TWSME \% increases more slowly. Figure 4 also indicates that there is little degradation of TWSME with thermal cycling in the absence of external load, especially for the material trained in the coil bound state.

The increase in TWSME \% observed as the training strain is increased is related to the amount of trained material present. On compressing the spring the strain across the diameter of the wire is non-uniform, being a maximum at the inner radius of the spring. This implies the existence of a volume of material in the central region of the wire which as not received sufficient strain to induce the preferential growth of martensite variants. As, during stressing the material, the number of martensite variants are progressively reduced from 24 to 1 this means that the number of variants present across the cross-section of the wire will vary continuously from 24 in the central region (non-trained) to 1 (completely trained) at the outer fiber, if sufficient strain has been achieved to produce only 1 variant at that location.

When the spring is compressed more there is a larger strain gradient across the crosssection and higher strains are present and hence more of the volume of the material has reached a strain sufficient to be trained and thus a greater TWSME will result, as was observed. However, as the strain increases irreversible plastic deformation may occur at the position of greatest strain (surface) which will not be recovered upon heating during subsequent thermal cycles. As seen in Figure 4 the amount of TWSME first increases rapidly with training strain (training strains of $0.8-1.25 \%$ ) after which the rate of increase of TWSME $\%$ decreases. This reflects the fact that the stress necessary to re-orient martensite variants increases as the number of different martensite variants are progressively reduced [8] and that more plastic deformation is produced the greater the deformation imposed.

Figure 5 shows the microstructure of a trained spring and a single martensite variant, in general observed in each grain as can be seen on comparing Figure 3 with Figure 5 . This is attributed to the presence of plates of stabilised stress induced martensite (SSIM), the stabilised variants being those which are crystallographically compatible with the deformation applied in training.

The amount of TWSME is directly related to the preferential formation of certain variants of thermal martensite on cooling. The ability of SSIM to influence martensite variant formation will determine the final amount of TWSME obtained and its subsequent reproducibility on thermal cycling. The capacity to orient thermal martensite depends on the amount of SSIM produced during training and the separation between SSIM plates. Higher training strains induce a greater amount of stress induced martensite (SIM) for a given training temperature and thus allow the stabilisation of a greater amount of SIM with a concomitant increase in TWSME, provided that plastic deformation does not occur.

Figure 6 shows the effect of time between quenching and training on the amount of TWSME \% developed [9]. The TWSME \% decreases sharply with time elapsed between quenching and training and after 1 hour the TWSME \% achievable is only approximately $15 \%$.

Figure 7 illustrates the changes in hot and cold lengths of the springs as a function of time between quenching and training [9]. The decrease in TWSME \% is thus due to both an increase in parent $\boldsymbol{B}$ phase deformation and a reduced deflection of the trained martensite. 
Quenching from $850^{\circ} \mathrm{C}$ into water at $20^{\circ} \mathrm{C}$ will result in a large quenched in vacancy supersaturation an a large inherited $\mathrm{DO}_{3}$ disorder [10] which are conducive to the rapid formation of the "retained martensite". This will reduce martensite plate mobility and hence the deformation imposed during compressing the spring cannot be totally accommodated by the growth of a preferred martensite variant with the result that the formation of a single martensite variant is inhibited and some plastic (non-recoverable) deformation occurs. Both of these factors will reduce the amount of TWSME developed during training.

\section{CONCLUSIONS}

1.- On increasing the training strain from 0.8 to $1.6 \%$ an increase in TWSME is produced, the maximum value being $60 \%$ measured after 1000 thermal cycles.

2.- For small values of training strain $(<1.25 \%)$, an increase in training strain brings about a large increase in TWSME, whereas on increasing training strain above $1.25 \%$ the rate of increase of TWSME is less pronounced.

3.- As the training strain increases a greater volume of the wire reaches a strain at which re-orientation of martensite variants can occur during training and hence the TWSME increases. However the fact that the stress necessary to re-orient martensite variants increases as the number of different martensite variants are progressively reduced and that more plastic deformation is produced the greater the deformation imposed brings about a decrease in the rate of increase in TWSME \% with training strain at training strains greater than $1.25 \%$.

4.- The TWSME \% developed in training depends on the mobility of the martensite variant interfaces, moreover of the amount of SSIM. The mobility of the martensite variant interfaces is related to the degree of the retained martensite as controlled by the vacancy supersaturation and degree of order. Hence the state of the material before training commences is also important in the development of a large TWSME.

\section{ACKNOWLEDGEMENTS}

JMG, JF and RF wish to acknowledge the financial support of the CICYT in programme number MAT92-1025-CO2-02.

\section{REFERENCES}

[1] T.A. Schroeder, C.M. Wayman, Scripta. Metall, 11, (1977), 225-230.

[2] J. Perkins, Materials Science and Engineering, 51, (1981), 181-192.

[3] J.M. Guilemany, J. Fernández, B.G. Mellor, Scripta Metall. et Mater, 24, (1990), 19411945.

[4] J.M. Guilemany, B.G. Mellor, J. Fernández, J. of Materials Sci. Letters, 11, (1992), 964967.

[5] J.M. Guilemany, J. Fernández, Scripta Metall. et Mater., 30, (1994), 59-61.

[6] J.M. Guilemany, J. Fernández, R. Franch, accepted for publication in La Revue de Métallurgie.

[7] J.M. Guilemany, J. Fernández, Scripta Met. et Mater., 30, (1994), 319-323.

[8] B.G. Mellor, "Martensite Transformation and the Shape Memory Effect", Proceedings of ECC Comett Course on the Science and Technology of Shape Memory Alloys, Barcelona, Spain February 1989 (Servei de Publicacions i Centre d'Informació i Documentació Acadèmica, Universitat de les Illes Balears, Palma de Mallorca, Spain, 1989) pp. 334-394.

[9] S. Willott, B. Eng. Project Report, Department of Mechanical Engineering, University of Southampton, UK, Report Number SP91/92 1992. 
[10] M. Mantel, R. Rapacioli, G. Guénin, "Ageing of Quenched Cu-Zn-Al Alloy in the Beta and Martensitic State", Proceedings of the International Conference on Martensitic Transformations (ICOMAT 86), Nara, Japan 26-30 August 1986 (The Japan Institute of Metals, 1986) pp 880-885.

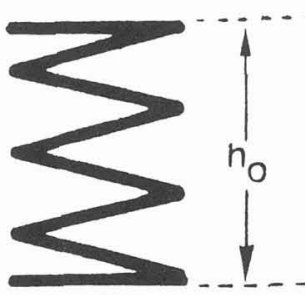

a)

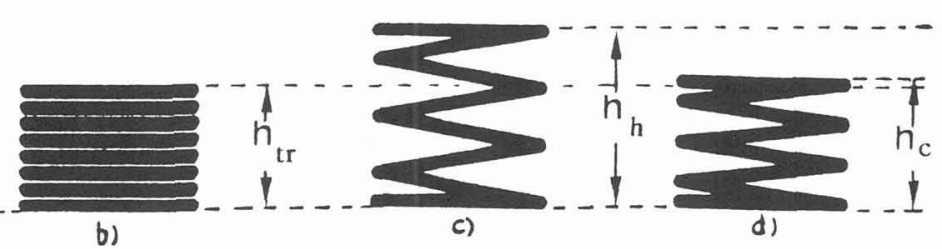

b) c)

d)

Figure 1. Schematic representation of the different shapes adopted by the trained springs. a) Original height of the spring. b) Height of spring during training. c) Height of the spring in its hot (B) shape. d) Height of the spring in its cold (martensite) shape.

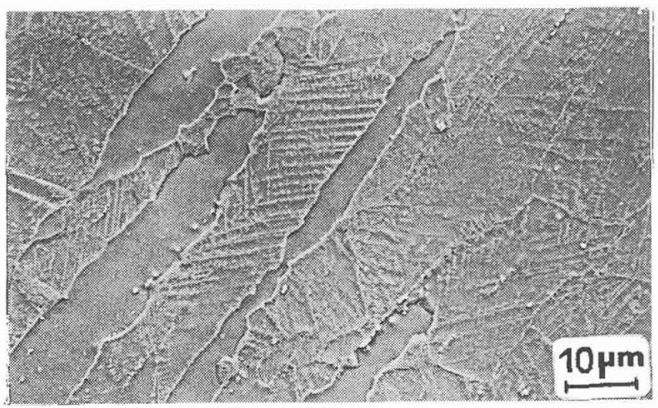

Figure 2. Original $\alpha+\beta$ structure of the springs.

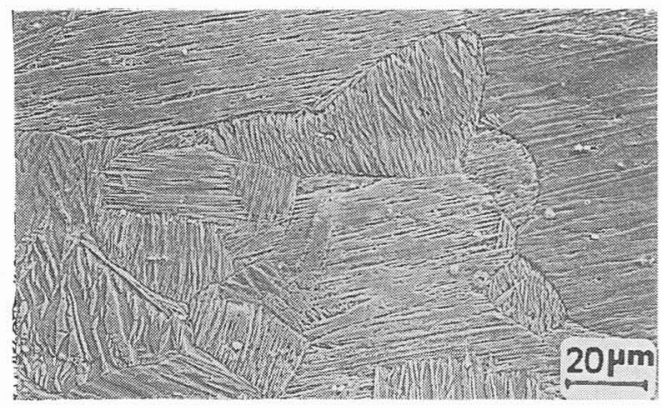

Figure 3. Martensitic structure after quenching from $850^{\circ} \mathrm{C}$.

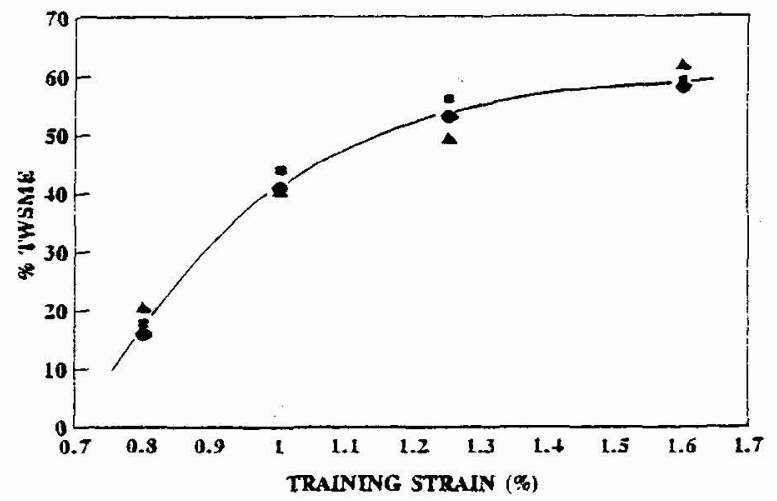

- Cycle $\mathrm{L} \triangle$ Cycle $100 \bullet$ Cycle 1000

Figure 4. TWSME \% as a function of training strain. 


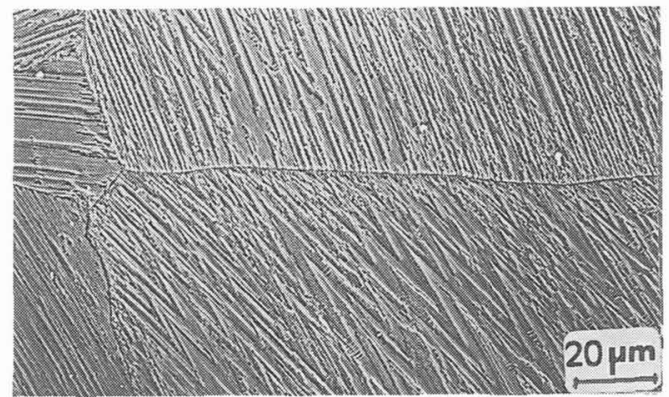

Figure 5. Structure of one trained spring.

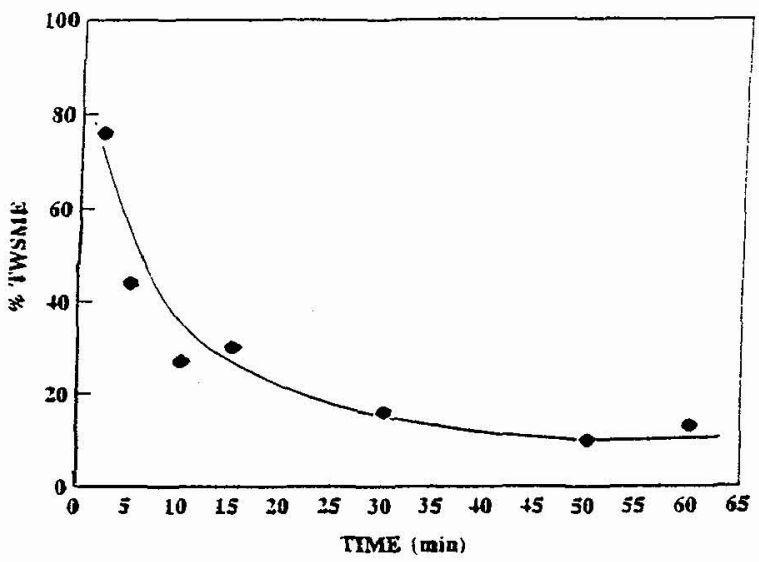

Figure 6. TWSME \% as a function of time between quenching after betatising and training.

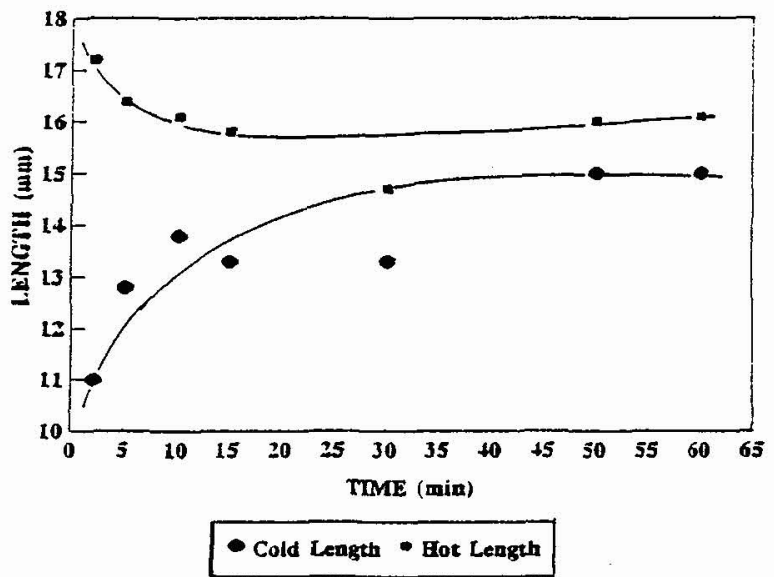

Figure 7. Parent and martensitic phase lengths as a function of time between quenching after betatising and training. 